\title{
Small Bowel Imaging in Managing Crohn's Disease Patients
}

\author{
Jörg G. Albert \\ Department of Medicine I, Johann Wolfgang Goethe University Frankfurt, Theodor-Stern-Kai 7, 60590 Frankfurt, Germany \\ Correspondence should be addressed to Jörg G. Albert, j.albert@med.uni-frankfurt.de
}

Received 12 September 2011; Accepted 29 November 2011

Academic Editor: P. Gionchetti

Copyright ( 2012 Jörg G. Albert. This is an open access article distributed under the Creative Commons Attribution License, which permits unrestricted use, distribution, and reproduction in any medium, provided the original work is properly cited.

\begin{abstract}
The small bowel is essential to sustain alimentation and small bowel Crohn's disease (CD) may severely limit its function. Small bowel imaging is a crucial element in diagnosing small bowel $\mathrm{CD}$, and treatment control with imaging is increasingly used to optimize the patients outcome. Thereby, capsule endoscopy, Balloon-assisted enteroscopy, and Magnetic resonance imaging have become key players to manage CD patients. In this review, role of small bowel imaging is detailed discussed for use in diagnosing and managing Crohn's disease patients.
\end{abstract}

\section{Introduction}

Crohn's disease $(\mathrm{CD})$ is a chronic inflammatory bowel disorder, and the patient might undergo recurring acute relapses. The disease is lifelong lasting and frequently manifests in the first decades of life. The small bowel is involved in more than two-thirds of patients. In some patients, refractory inflammation or chronic strictures of the small bowel are responsible for a debilitating course of the disease that might lead into malnutrition and a severely reduced quality of life. Therefore, the small bowel warrants special attention in diagnosing and treating $\mathrm{CD}$.

Ideally, diagnostic tools that reveal small bowel CD should be without objection to repeat them, easy and promptly to apply, and well tolerable. Many of these requirements are satisfied by modern diagnostics and imaging techniques. Recently, the small bowel has come within reach of easy-toapply endoscopy, that is, capsule endoscopy (CE), balloonassisted enteroscopy (BAE), and spiral enteroscopy. Highquality cross-sectional imaging complements endoscopy, and percutaneous ultrasound (US) and magnetic-resonance imaging (MRI) are at hand for an optimal steering instrument of treatment regimens.

Recently, endoscopy is increasingly used to control the effect of medical treatment in clinical practice of $C D$ patients. When former studies were referring on symptom improvement, only [1], more and more studies include "objective" parameters such as endoscopic or radiologic findings to supervise the patient [2-5]. Primarily, the concept of endoscopic surveillance was established in the detection of postoperative recurrence some 20 years ago [3]. With the evidence of complete mucosal healing in modern immunomodulation therapies, arguments for endoscopic treatment control are getting stronger $[4,5]$.

This review updates on new small bowel imaging methods and their impact on managing small bowel CD.

\section{Capsule Endoscopy}

Small bowel video CE offers a noninvasive and easy-toapply investigation of the small bowel. The video capsule is ingested and passes the intestinal tract by use of natural peristalsis. Thereby, images are continuously acquired until battery exhaustion and are registered at the storage device that the patient wears as his belt. Imaging data are afterwards reviewed by a specialist on a computer workstation. Most systems offer online visualization of the endoscopic procedure, but this feature is mainly used to confirm passage progress and not to detect a lesion. At present, there are several commercially available CE systems on the market that differ somehow in terms of technical details or software features: PillCam SB2, Given Imaging, Yoqneam, Israel (http://www.givenimaging.com/); EndoCapsule, Olympus Europe GmbH, Hamburg, Deutschland, (http://www.olympuseuropa.com/endoscopy/); CapsoVision, Saratoga, Ca, USA, (http://www.capsovision.com/); OMOM, Chongqing 
TABLE 1: Four capsule endoscopes are available at present.

\begin{tabular}{lccccc}
\hline Capsule & Company & Size $(\mathrm{mm})$ & Frame rate (Images/s) & Field of view & Acquisition time (hours) \\
\hline PillCam SB 2 & Given Imaging, Israel & $26 \times 11$ & 2 & $156^{\circ}$ & $8(\mathrm{SB} 2) ; \mathrm{ca} .12-16(\mathrm{SB} 2 \mathrm{~L})$ \\
EndoCapsule & Olympus, Japan & $26 \times 11$ & 2 & $145^{\circ}$ & $>8$ \\
MiroCam & IntroMedic, Korea & $25 \times 11$ & 3 & - & $140^{\circ}$ \\
OMOM & Chongqing Jinshan Science, China & $28 \times 13$ & 2 or 1 & 360 & 8 \\
CapsoVision & CapsoVision Inc. & $31 \times 11.3$ & $0-5$ & 11 & 15 \\
\hline
\end{tabular}

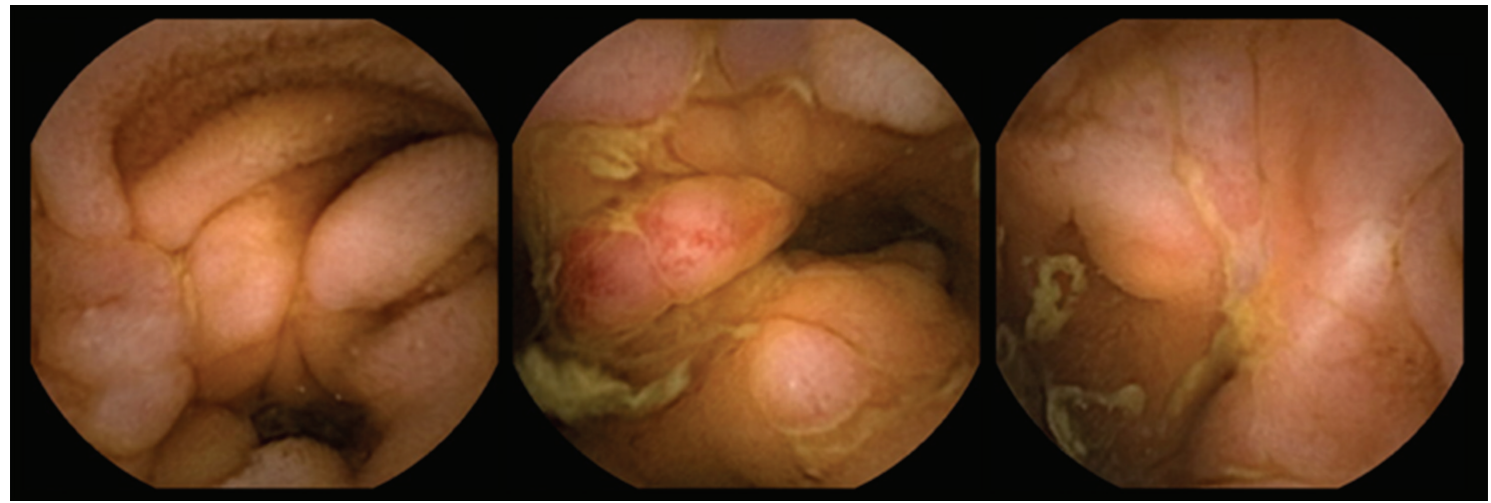

FIGURE 1: Crohn's disease of the small bowel in capsule endoscopy: multiple small ulcerations all over the ileum and jejunum, scarring alterations of the small bowel.

Jinshan Science, Beijing, China, (http://www.cqjs.net/); Miro-Cam, IntroMedic, Seoul, Korea (http://www.intromedic.com/). In the USA, only the PillCam SB2 and the EndoCapsule are currently approved by the US Food and Drug Administration, and in Europe, all the four systems can be purchased in most countries. Widely spread is the PillCam SB 2 capsule that has been used for almost all studies on CE in CD. The PillCam SB2 uses a CMOS chip with a resolution of $0.1 \mathrm{~mm}$ at a magnification of $1: 8$. Battery life is $8 \mathrm{~h}(\mathrm{SB} 2)$ to about 12-16 hours (SB 2L); Table 1; Figure 1.

$\mathrm{CE}$ is usually not used in patients with intestinal strictures or potential stenosis for fear of retention. Dysphagia is a relative contraindication for $\mathrm{CE}$, but the capsule might be placed in the duodenum by means of esophagogastroduodenoscopy (EGD) in case of swallowing disorders or gastroparesis. Pregnancy and any implanted medical device are still considered contraindications, but there is an increasing experience with the use of the PillCam capsule in patients with cardiac pacemakers or defibrillators. Thereby, interference for disadvantage of the patient has not been reported [22]. The main limitation of the capsule is the lack to take biopsies or to perform interventions, the difficulty to exactly localize identified lesions, and to control its movement. By administering patency capsule before doing video CE, capsule retention can be reliably prevented $[23,24]$. The patency system (i.e., given AGILE patency capsule) is designed to determine which patients with known or suspected intestinal strictures can safely ingest a video capsule endoscope. The capsule is of similar size to the endoscopy capsule, but is made of lactose and barium and dissolves within 32 to 72 hours of entering the GI tract. Excretion of the intact capsule without symptoms predicts the uncomplicated passage of the wireless capsule endoscope.

\section{Balloon-Assisted Enteroscopy (BAE)}

Balloon-assisted enteroscopy (BAE) was first introduced in 2003 [25]. BAE allows deeper intubation of the SB compared with push enteroscopy (PE) and ileocolonoscopy (IC). BAE involves push-and-pull maneuvers for deep intubation of the small bowel [26], and single- and double-balloon enteroscopes (SBE and DBE) are presently available [27]; Table 2.

Rate of complete small bowel investigations seems to be more regularly achievable using double-balloon instead of single-balloon technique as reported in randomized studies (Table 3), but therapeutic impact was similar to SBE and DBE. Preference for SBE or DBE depends on the experience and predilection of the endoscopic centre.

Carbon dioxide insufflation instead of using ambient air increases intubation depth and significantly reduces inconvenience of the patient and may therefore be preferred for all balloon-enteroscopy interventions $[28,29]$. Complication rates are low in diagnostic $\mathrm{BAE}(<5 \%)$ and include pancreatitis $(<1 \%)$, bleeding, and perforation, and rate of complications increases in therapeutic interventions [30].

\section{Spiral Enteroscopy (SE) and Others}

Enteroscopy with the Endo-Ease system (Spirus Medical, Stoughton, MA) uses a spiral-shaped overtube of $118 \mathrm{~cm}$ 
TABLE 2: Balloon-assisted enteroscopy. Technical data of the scopes that are presently available.

\begin{tabular}{|c|c|c|c|c|c|c|c|}
\hline Device & Company & $\begin{array}{l}\text { Working channel } \\
(\mathrm{mm})\end{array}$ & $\begin{array}{c}\text { Length } \\
(\mathrm{mm})\end{array}$ & $\begin{array}{l}\text { Working length } \\
(\mathrm{mm})\end{array}$ & $\begin{array}{c}\text { Diameter of } \\
\text { distal part }(\mathrm{mm})\end{array}$ & $\begin{array}{c}\text { Length of } \\
\text { overtube }(\mathrm{mm})\end{array}$ & $\begin{array}{l}\text { Diameter of overtube } \\
(\mathrm{mm})\end{array}$ \\
\hline DBE EN-450P5 & Fuji & 2.2 & 2300 & 2000 & 8.5 & 1450 & $\begin{array}{c}12.2 \text { (outer diameter) } \\
8.7-10 \text { (inner diameter) }\end{array}$ \\
\hline DBE EN-450T5 & Fuji & 2.8 & 2300 & 2000 & 9.4 & 1450 & $\begin{array}{c}13,2 \text { (outer diameter) } \\
9.8-10.8 \text { (inner diameter) }\end{array}$ \\
\hline SBE SIF-Q180 & Olympus & 2.8 & 2300 & 2000 & 9.2 & 1320 & $13 \mathrm{~mm}$ (ST-SB1) \\
\hline
\end{tabular}

TABLE 3: Comparison of single-balloon (SBE) or double-balloon technique (DBE) in prospective, randomized studies.

\begin{tabular}{|c|c|c|c|c|c|c|c|c|}
\hline \multirow{2}{*}{ Author } & \multirow[b]{2}{*}{ Year } & \multirow[b]{2}{*}{$n$} & \multicolumn{2}{|c|}{ Complete enteroscopy } & \multicolumn{2}{|c|}{ Diagnostic yield } & \multicolumn{2}{|c|}{ Therapeutic yield } \\
\hline & & & SBE & DBE & SBE & DBE & SBE & $\mathrm{DBE}$ \\
\hline May et al. [6] & 2010 & 100 & $22 \%$ & $66 \%$ & $42 \%$ & $52 \%$ & $42 \%$ & $52 \%$ \\
\hline Domagk et al. [7] & 2011 & 150 & $11 \%$ & $18 \%$ & $37 \%$ & $43 \%$ & $5 \%$ & $9 \%$ \\
\hline Takano et al. [8] & 2011 & 38 & $0 \%$ & $57 \%$ & $61 \%$ & $50 \%$ & $28 \%$ & $35 \%$ \\
\hline
\end{tabular}

with a spiral of $0.55 \mathrm{~cm}$ high and $22 \mathrm{~cm}$ long and can be used with enteroscopes of less than $9.4 \mathrm{~mm}$ in diameter. The enteroscope is advanced or withdrawn with rotatory clockwise and counterclockwise movements of the spiral. Endoscopy of the small bowel by SE is reported to be safe [31] and seems to reduce the examination time, but the insertion depth is minor in comparison to DBE [32-34]. In Crohn's disease patients, SE has rarely been performed up to now.

\section{Radiology in Imaging Small Bowel Crohn's Disease}

Visualization of the small bowel with cross-sectional imaging methods requires distension of the intestines to identify the configuration of the bowel loops and to improve characterization of the bowel wall with luminal contrast. This is achieved by inserting a nasojejunal tube into the proximal small bowel (enteroclysis) or with oral intake of the luminal contrast medium (enterography). Conventional fluoroscopy (small bowel follow-through and small bowel enteroclysis) has thereby almost completely been replaced by crosssectional imaging methods. Computed tomography (CT) and MRI are available as CT-enterography/CT-enteroclysis (CT-E) or MR-enterography/MR-enteroclysis (MR-E) with oral intake providing similar quality images but with an improved patient comfort over tube-assisted infusion of enteral contrast $[15,35,36]$. MR and CT equally provide excellent information on inflammatory alterations of the small bowel and also of extraluminal complications (abscess, fistula), thus adding useful information on endoscopic investigations; Table 4.

Large lifetime doses of radiation are a concern particularly in young patients. CD patients are at risk for an increased exposure, and the often young age at the initial diagnosis has a significant influence on lifetime risk [37]. Radiation doses of more than $100 \mathrm{mSv}$ may be observed in some patients. Lack of radiation exposure and excellent soft tissue contrast argue for use of MRI in CD patients and against fluoroscopy or CT [38-42].

\section{Percutaneous Ultrasonography for Detection of Small Bowel Crohn's Disease}

Percutaneous ultrasonography (US) is useful to detect small bowel CD and to reveal extraintestinal complications, for example, abscess or fistula. Sensitivity of the technique is improved with the use of enteral contrast medium, such as polyethylene glycol [41]. Overall accuracy might be minor to endoscopy, but an experienced investigator can beneficially use US as an initial diagnostic tool for managing CD patients [42].

\section{Diagnosing Small Bowel Crohn's Disease: Endoscopy in Comparison to Radiologic Imaging}

Small bowel endoscopy and MR-E/CT-E are accepted as a diagnostic standard to evaluate small bowel CD, but diagnostic sequence and clear definition of applying endoscopy versus cross-sectional imaging is under debate. Meta-analysis of studies comparing diagnostic yield and value of CT-E, MR-E, CE, and other methods were published in 2006 [43] and 2010 [44]. Thereby, higher sensitivity of endoscopic methods, for example, CE, to detect small bowel lesions was clearly demonstrated; Table 5.

Next to high sensitivity, endoscopy has an excellent negative predictive value to exclude manifestation of small bowel CD. But endoscopic and radiologic findings are far from being pathognomonic, and small bowel ulceration may similarly be compatible with chronic inflammatory, neoplastic, and infectious origin or might be secondary to NSAID intake. In a cohort of patients who were suspected to be afflicted with small bowel CD, 37\% of 102 patients were initially diagnosed with small bowel ulcerations in $\mathrm{CE}$, but in only $13 \%$ the diagnosis of CD was maintained at one year of followup [45]. This reflects the "old" wisdom, that diagnosing CD is based on many clinical data including followup of the patient. Even if some features of small bowel lesions might rather suggest CD (irregular and longitudinal 
TABLE 4: Comparing pros and cons of CT versus MRI in use in Crohn's disease patients; CT-enterography/CT-enteroclysis (CT-E) or MRenterography/MR-enteroclysis (MR-E).

\begin{tabular}{|c|c|c|c|}
\hline \multicolumn{2}{|l|}{ CT-E } & \multicolumn{2}{|c|}{ MR-E } \\
\hline Pro & Con & Pro & Con \\
\hline $\begin{array}{l}\text { High resolution in contrast-rich } \\
\text { objects (e.g., bone versus parenchyma) }\end{array}$ & & $\begin{array}{l}\text { Excellent contrast in soft } \\
\text { tissues; contrast uptake into } \\
\text { tissues is well visualized }\end{array}$ & \\
\hline $\begin{array}{l}\text { Fast acquisition time, minor motion } \\
\text { artifacts }\end{array}$ & & & $\begin{array}{l}\text { Increased acquisition time, } \\
\text { prone to motion artifacts }\end{array}$ \\
\hline Widely spread technique & & & $\begin{array}{l}\text { Higher cost and less } \\
\text { available }\end{array}$ \\
\hline \multirow[t]{4}{*}{$\begin{array}{l}\text { Abdomen and pelvis are a one-step } \\
\text { investigation }\end{array}$} & & & $\begin{array}{c}\text { Abdomen/pelvis are usually } \\
\text { different examination } \\
\text { protocols }\end{array}$ \\
\hline & Radiation exposure & No radiation exposure & \\
\hline & $\begin{array}{l}\text { Specific side effects of contrast } \\
\text { medium }\end{array}$ & & $\begin{array}{l}\text { Specific side effects of } \\
\text { contrast medium }\end{array}$ \\
\hline & & & $\begin{array}{l}\text { Restriction in pace-maker } \\
\text { patients and so forth }\end{array}$ \\
\hline
\end{tabular}

TABLE 5: Comparison of diagnostic yield or sensitivity in cross-sectional imaging and endoscopy in diagnosing small bowel Crohn's disease; CTE: computed tomography enterography; MRI: magnetic resonance imaging.

\begin{tabular}{|c|c|c|c|c|c|c|}
\hline Author & Year of publication & $N$ & Capsule endoscopy & \multicolumn{2}{|c|}{ Comparator (cross-sectional imaging) } & $\begin{array}{c}\text { Statistical } \\
\text { significance }\end{array}$ \\
\hline Eliakim et al. [9] & 2004 & 35 & $77 \%$ & CTE & $20 \%$ & $P<0.05$ \\
\hline Voderholzer et al. [10] & 2005 & 41 & $25 / 41(61 \%)$ & CTE & $12 / 41(29 \%)$ & $P=0.004$ \\
\hline Hara et al. [11] & 2006 & 17 & $12 / 17(71 \%)$ & CT & $9 / 17(53 \%)$ & n.s. \\
\hline Solem et al. [12] & 2008 & 28 & $83 \%$ & CTE & $83 \%$ & n.s. \\
\hline Albert et al. [13] & 2005 & 52 & $25 / 27(93 \%)$ & MRI & $21 / 27(78 \%)$ & n.s. \\
\hline Golder et al. [14] & 2006 & 18 & $12 / 18(66 \%)$ & MRI & $1 / 18(5 \%)$ & $P=0.016$ \\
\hline Jensen et al. [15] & 2011 & 93 & $100 \%$ & $\begin{array}{l}\text { MRI and } \\
\text { CTE }\end{array}$ & $\begin{array}{c}81 \% \text { (MRI) } 76 \% \\
\text { (CTE) }\end{array}$ & $\begin{array}{c}P<0.05 \text { (for } \\
\text { proximal } \\
\text { small bowel) }\end{array}$ \\
\hline
\end{tabular}

ulcerations, multiple locations, and cobble stone aspect of the small bowel) than NSAID use (circular ulcerations, webs) or neoplasia (circumscribed lesion), these identifiers must be interpreted cautiously before labeling a patient to be affected by CD.

\section{Diagnosing Small Bowel Crohn's Disease: Suspected Crohn's Disease}

In suspected CD, ileocolonoscopy is still the reference standard in the diagnostic algorithm. Consensus conferences therefore advised to keep to a specific diagnostic sequence in suspected CD: first, ileocolonoscopy is used to diagnose ileitis terminalis or colitis, this is followed by cross-sectional imaging to identify proximal CD or extraenteric lesions, and $\mathrm{CE}$ is regarded a final identifier for detection of small bowel lesions that are reason for unexplained symptoms $[46,47]$. These recommendations have not yet considered recent study results demonstrating equal validity to detect terminal ileitis for CT-E, MR-E, and CE. Moreover, significantly better detection of proximal small bowel involvement may be expected for CE [15]. Moreover, high negative predictive value of CE of 90 to $100 \%$ suggests using CE to exclude CD in suspected disease cases. Therefore, CE could be considered an early step in suspected CD and nonconclusive colonoscopy in the future. To exclude neoplastic and infectious disease, flexible enteroscopy should regularly be performed to take biopsies in lesions found by CE. Cross-sectional imaging (e.g., US, MRI) is indicated to screen for extraintestinal disease. Studies are not yet available that might support the use of CE to investigate the small bowel plus the colon in a "one-step shopping" approach using the colon capsule endoscope.

\section{Diagnosing Small Bowel Crohn's Disease: Established Crohn's Disease}

In established CD, value of cross-sectional imaging (e.g., MRI) surpasses endoscopic information in many clinical scenarios such as the septic patient, and acute onset of severe complaints and pain. Severe inflammations of bowel segments, suppurative disease, and conglomerate tumor or 
TABLE 6: Balloon dilation for symptomatic small bowel strictures with the use of balloon-assisted enteroscopy; Small bowel strictures in anastomotic and nonanastomotic Crohn's disease.

\begin{tabular}{|c|c|c|c|c|c|c|}
\hline \multirow{2}{*}{ Author } & \multirow[b]{2}{*}{ Year } & \multirow[b]{2}{*}{$n$} & \multicolumn{3}{|c|}{ Balloon dilation } & \multirow{2}{*}{ Complication } \\
\hline & & & Technical success & Clinical response & Failed & \\
\hline Yamamoto et al. [16] & 2004 & 6 & 6 & 6 & 6 & None \\
\hline Pohl et al. [17] & 2007 & 19 & 8 & 6 & 13 & None \\
\hline Fukumoto et al. [18] & 2007 & 23 & 22 & 17 & $\begin{array}{c}2 \text { (Surgery) } 4 \\
\text { (repeated } \\
\text { dilation) }\end{array}$ & None \\
\hline Despott et al. [19] & 2009 & 11 & 9 & 8 & 2 & Perforation $(n=1)$ \\
\hline Hirai et al. [20] & 2010 & 25 & 18 & 18 & 7 & $n=2$ \\
\hline Kondo et al. [21] & 2010 & 12 & 8 & 7 & 1 & None \\
\hline
\end{tabular}

fistulae are thereby detected. Performance of ileocolonoscopy and/or small bowel endoscopy is necessary to discriminate inflammatory from chronic-scarring bowel changes or strictures. Indication for BAE has to be balanced against CE preferring flexible endoscopy in suspicion of high grade strictures or in case the "patency capsule" failed to pass the intestines.

\section{Colitis with an Unclassified Type of Inflammatory Bowel Disease (IBDU)}

In colitis with an unclassified type of inflammatory bowel disease (IBDU), small bowel inflammation could be the clue to confirm the diagnosis of $\mathrm{CD}$ in some patients. The diagnosis of IBDU had been revised and changed to CD in 15\% of 120 patients in one study in which small bowel ulcerations were detected $[48,49]$. Discrete findings should not mislead to revise the diagnosis, despite [50], and negative small bowel CE might not completely exclude $\mathrm{CD}$ - for example, of the colon [49].

In the postoperative situation, endoscopic surveillance of the patient has been recommended [47], and endoscopy seems essential to discriminate inflammatory from noninflammatory bowel alterations. CE might replace ileocolonoscopy to detect recurrence: accuracy of CE to detect inflammation near to the anastomosis is similar to conventional colonoscopy, but proximal disease is exclusively visualized by CE $[41,51,52]$.

\section{Endoscopic Treatment in Crohn's Disease}

Flexible endoscopy offers treatment options for CD strictures in selected cases. Balloon dilation has been expanded from colonic and anastomotic stricture to the whole of the small bowel by use of BAE, and symptomatic small bowel strictures may be treated at anastomotic and nonanastomotic sites with a justifiable risk profile (Table 6). Balloon dilation might well be repeated in recurring strictures.

\section{Imaging for Treatment Control}

Imaging is used to control treatment and to assess prognosis in Crohn's disease patients, but this is far from routine practice. New concepts of modern treatment regimes that aim to attain complete mucosal healing support to verify treatment success using diagnostic procedures and a new verve for imaging to help managing $\mathrm{CD}$ patients may recently be noticed [53]. Nevertheless, studies keep relying on clinical outcome without supporting subjective endpoints such as imaging data [1]. But introduction of objective study outcomes, for example, by assessing endoscopic activity of $\mathrm{CD}$ before and after treatment is increasingly reported, for example, in the postoperative situation [2-5]. Interestingly, we know for over 20 years that endoscopic activity predicts course of the disease in high-risk, postoperative patients [3], and endoscopic treatment control in this patient group is well established [54]. Control of mucosal healing has been used to assess treatment efficacy in ulcerative colitis, but in $\mathrm{CD}$, this concept has only emerged after biological therapies have been evaluated in clinical trials. Even if mucosal healing has been shown to reduce hospitalizations and surgery, strong correlation of mucosal healing and symptom improvement has not been proven yet [5]. Today, in clinical practice, endoscopy is used to assess mucosal healing in patients with persistent symptoms despite therapy and when treatment discontinuation is considered. Further studies have to provide the value of managing all $\mathrm{CD}$ patients with endoscopic or radiologic imaging.

\section{Conclusion}

Small bowel imaging is a crucial element in diagnosing small bowel CD, and CE, BAE, and MRI have become key players to manage $\mathrm{CD}$ patients. Treatment control is strongly advised in the patient who had formerly undergone bowel resection, but is increasingly used to testify treatment success in many patients. Endoscopy is indispensable for diagnosis at first presentation, and cross-sectional imaging is the firstline diagnostic means in established disease and presentation with severe disease. Thus, complementary use of cross-sectional imaging and endoscopy is essential for the best benefit of the patient.
Abbreviation
APC: Argon plasma coagulation
BAE: Balloon-assisted enteroscopy 


$\begin{array}{ll}\text { CE: } & \text { Capsule endoscopy } \\ \text { CT: } & \text { Computed tomography } \\ \text { CT-E: } & \text { CT-enteroclysis/enterography } \\ \text { DBE: } & \text { Double-balloon enteroscopy } \\ \text { EGD: } & \text { Esophagogastroduodenoscopy } \\ \text { ERC: } & \text { Endoscopic retrograde cholangiography } \\ \text { IBDU: } & \text { Unclassified type of inflammatory bowel } \\ & \text { disease } \\ \text { MR-E: } & \text { MR-enteroclysis/enterography } \\ \text { MRI: } & \text { Magnetic resonance imaging } \\ \text { NSAID: } & \text { Nonsteroidal anti-inflammatory drugs } \\ \text { SBE: } & \text { Single-balloon enteroscopy } \\ \text { TTS: } & \text { Through the scope } \\ \text { US: } & \text { Percutaneous ultrasonography. }\end{array}$

\section{References}

[1] J. F. Colombel, W. J. Sandborn, W. Reinisch et al., "Infliximab, azathioprine, or combination therapy for Crohn's disease," The New England Journal of Medicine, vol. 362, no. 15, pp. 1383-1395, 2010.

[2] M. Regueiro, W. Schraut, L. Baidoo et al., "Infliximab prevents Crohn's disease recurrence after ileal resection," Gastroenterology, vol. 136, no. 2, pp. 441-450, 2009.

[3] P. Rutgeerts, K. Geboes, G. Vantrappen, J. Beyls, R. Kerremans, and M. Hiele, "Predictability of the postoperative course of Crohn's disease," Gastroenterology, vol. 99, no. 4, pp. 956-963, 1990.

[4] G. van Assche, S. Vermeire, and P. Rutgeerts, "Mucosal healing and anti TNFs in IBD," Current Drug Targets, vol. 11, no. 2, pp. 227-233, 2010.

[5] A. Efthymiou, N. Viazis, G. Mantzaris et al., "Does clinical response correlate with mucosal healing in patients with Crohn's disease of the small bowel? A prospective, case-series study using wireless capsule endoscopy," Inflammatory Bowel Diseases, vol. 14, no. 11, pp. 1542-1547, 2008.

[6] A. May, M. Färber, I. Aschmoneit et al., "Prospective multicenter trial comparing push-and-pull enteroscopy with the singleand double-balloon techniques in patients with small-bowel disorders," American Journal of Gastroenterology, vol. 105, no. 3, pp. 575-581, 2010.

[7] D. Domagk, P. Mensink, H. Aktas et al., "Single- vs. doubleballoon enteroscopy in small-bowel diagnostics: a randomized multicenter trial," Endoscopy, vol. 43, no. 6, pp. 472-476, 2011.

[8] N. Takano, A. Yamada, H. Watabe et al., "Single-balloon versus double-balloon endoscopy for achieving total enteroscopy: a randomized, controlled trial," Gastrointestinal Endoscopy, vol. 73, no. 4, pp. 734-739, 2011.

[9] R. Eliakim, A. Suissa, K. Yassin, D. Katz, and D. Fischer, "Wireless capsule video endoscopy compared to barium followthrough and computerised tomography in patients with suspected Crohn's disease-final report," Digestive and Liver Disease, vol. 36, no. 8, pp. 519-522, 2004.

[10] W. A. Voderholzer, J. Beinhoelzl, P. Rogalla et al., "Small bowel involvement in Crohn's disease: a prospective comparison of wireless capsule endoscopy and computed tomography enteroclysis," Gut, vol. 54, no. 3, pp. 369-373, 2005.

[11] A. K. Hara, J. A. Leighton, R. I. Heigh et al., "Crohn disease of the small bowel: preliminary comparison among CT enterography, capsule endoscopy, small-bowel follow-through, and ileoscopy," Radiology, vol. 238, no. 1, pp. 128-134, 2006.
[12] C. A. Solem, E. V. Loftus, J. G. Fletcher et al., "Small-bowel imaging in Crohn's disease: a prospective, blinded, 4-way comparison trial," Gastrointestinal Endoscopy, vol. 68, no. 2, pp. 255-266, 2008.

[13] J. G. Albert, F. Martiny, A. Krummenerl et al., "Diagnosis of small bowel Crohn's disease: a prospective comparison of capsule endoscopy with magnetic resonance imaging and fluoroscopic enteroclysis," Gut, vol. 54, no. 12, pp. 1721-1727, 2005.

[14] S. K. Gölder, A. G. Schreyer, E. Endlicher et al., "Comparison of capsule endoscopy and magnetic resonance (MR) enteroclysis in suspected small bowel disease," International Journal of Colorectal Disease, vol. 21, no. 2, pp. 97-104, 2006.

[15] M. D. Jensen, T. Nathan, S. R. Rafaelsen, and J. Kjeldsen, "Diagnostic accuracy of capsule endoscopy for small bowel Crohn's disease is superior to that of MR enterography or CT enterography," Clinical Gastroenterology and Hepatology, vol. 9, no. 2, pp. 124-129, 2011.

[16] H. Yamamoto, H. Kita, K. Sunada et al., "Clinical outcomes of double-balloon endoscopy for the diagnosis and treatment of small-intestinal diseases," Clinical Gastroenterology and Hepatology, vol. 2, no. 11, pp. 1010-1016, 2004.

[17] J. Pohl, A. May, L. Nachbar, and C. Ell, "Diagnostic and therapeutic yield of push-and-pull enteroscopy for symptomatic small bowel Crohn's disease strictures," European Journal of Gastroenterology and Hepatology, vol. 19, no. 7, pp. 529-534, 2007.

[18] A. Fukumoto, S. Tanaka, H. Yamamoto et al., "Diagnosis and treatment of small-bowel stricture by double balloon endoscopy," Gastrointestinal Endoscopy, vol. 66, no. 3, pp. S108S112, 2007.

[19] E. J. Despott, A. Gupta, D. Burling et al., "Effective dilation of small-bowel strictures by double-balloon enteroscopy in patients with symptomatic Crohn's disease (with video)," Gastrointestinal Endoscopy, vol. 70, no. 5, pp. 1030-1036, 2009.

[20] F. Hirai, T. Beppu, S. Sou, T. Seki, K. Yao, and T. Matsui, "Endoscopic balloon dilatation using double-balloon endoscopy is a useful and safe treatment for small intestinal strictures in crohn's disease," Digestive Endoscopy, vol. 22, no. 3, pp. 200-204, 2010.

[21] J. Kondo, H. Iijima, T. Abe et al., "Roles of double-balloon endoscopy in the diagnosis and treatment of Crohn's disease: a multicenter experience," Journal of Gastroenterology, vol. 45, no. 7, pp. 713-720, 2010.

[22] D. Bandorski, W. Irnich, M. Brück, N. Beyer, W. Kramer, and R. Jakobs, "Capsule endoscopy and pacemakers: investigation for possible interference," Endoscopy, vol. 40, no. 1, pp. 36-39, 2008.

[23] C. Signorelli, E. Rondonotti, F. Villa et al., "Use of the Given ${ }^{\circledR}$ Patency System for the screening of patients at high risk for capsule retention," Digestive and Liver Disease, vol. 38, no. 5, pp. 326-330, 2006.

[24] C. Spada, M. E. Riccioni, and G. Costamagna, "Patients with known small bowel stricture or with symptoms of small bowel obstruction secondary to crohn's disease should not perform video capsule endoscopy without being previously tested for small bowel patency," American Journal of Gastroenterology, vol. 102, no. 7, pp. 1542-1543, 2007.

[25] H. Yamamoto, Y. Sekine, Y. Sato et al., "Total enteroscopy with a nonsurgical steerable double-balloon method," Gastrointestinal Endoscopy, vol. 53, no. 2, pp. 216-220, 2001.

[26] A. May, L. Nachbar, M. Schneider, M. Neumann, and C. Ell, "Push-and-pull enteroscopy using the double-balloon technique: method of assessing depth of insertion and training 
of the enteroscopy technique using the Erlange endo-trainer," Endoscopy, vol. 37, no. 1, pp. 66-70, 2005.

[27] L. B. Gerson, J. T. Flodin, and K. Miyabayashi, "Balloon-assisted enteroscopy: technology and troubleshooting," Gastrointestinal Endoscopy, vol. 68, no. 6, pp. 1158-1167, 2008.

[28] D. Domagk, M. Bretthauer, P. Lenz et al., "Carbon dioxide insufflation improves intubation depth in double-balloon enteroscopy: a randomized, controlled, double-blind trial," Endoscopy, vol. 39, no. 12, pp. 1064-1067, 2007.

[29] F. Hirai, T. Beppu, T. Nishimura et al., "Carbon dioxide insufflation compared with air insufflation in double-balloon enteroscopy: a prospective, randomized, double-blind trial," Gastrointestinal Endoscopy, vol. 73, no. 4, pp. 743-749, 2011.

[30] O. Möschler, A. May, M. K. Müller, C. Ell, and German DBE Study Group, "Complications in and performance of doubleballoon enteroscopy (DBE): results from a large prospective DBE database in Germany," Endoscopy, vol. 43, no. 6, pp. 484489, 2011.

[31] J. R. Judah, P. V. Draganov, Y. Lam, W. Hou, and J. M. Buscaglia, "Spiral enteroscopy is safe and effective for an elderly United States population of patients with numerous comorbidities," Clinical Gastroenterology and Hepatology, vol. 8, no. 7, pp. 572-576, 2010.

[32] A. May, H. Manner, I. Aschmoneit, and C. Ell, "Prospective, cross-over, single-center trial comparing oral double-balloon enteroscopy and oral spiral enteroscopy in patients with suspected small-bowel vascular malformations," Endoscopy, vol. 43, no. 6, pp. 477-483, 2011.

[33] T. Frieling, J. Heise, W. Sassenrath, A. Hülsdonk, and C. Kreysel, "Prospective comparison between double-balloon enteroscopy and spiral enteroscopy," Endoscopy, vol. 42, no. 11, pp. 885-888, 2010.

[34] E. Perez-Cuadrado, R. Macenlle, J. Iglesias, R. Fabra, and D. Lamas, "Usefulness of oral video push enteroscopy in Crohn's disease," Endoscopy, vol. 29, no. 8, pp. 745-747, 1997.

[35] G. Masselli, E. Casciani, E. Polettini, and G. Gualdi, "Comparison of MR enteroclysis with MR enterography and conventional enteroclysis in patients with Crohn's disease," European Radiology, vol. 18, no. 3, pp. 438-447, 2008.

[36] A. G. Schreyer, A. Geissler, H. Albrich et al., "Abdominal MRI after enteroclysis or with oral contrast in patients with suspected or proven Crohn's disease," Clinical Gastroenterology and Hepatology, vol. 2, no. 6, pp. 491-497, 2004.

[37] J. M. Peloquin, D. S. Pardi, W. J. Sandborn et al., "Diagnostic ionizing radiation exposure in a population-based cohort of patients with inflammatory bowel disease," American Journal of Gastroenterology, vol. 103, no. 8, pp. 2015-2022, 2008.

[38] D. J. Brenner and E. J. Hall, "Computed tomography-an increasing source of radiation exposure," The New England Journal of Medicine, vol. 357, no. 22, pp. 2277-2284, 2007.

[39] A. M. Gaca, T. A. Jaffe, S. Delaney et al., "Radiation doses from small-bowel follow-through and abdomen/pelvis MDCT in pediatric Crohn disease," Pediatric Radiology, vol. 38, no. 3, pp. 285-291, 2008.

[40] A. N. Desmond, K. O’Regan, C. Curran et al., "Crohn's disease: factors associated with exposure to high levels of diagnostic radiation," Gut, vol. 57, no. 11, pp. 1524-1529, 2008.

[41] L. Biancone, E. Calabrese, C. Petruzziello et al., "Wireless capsule endoscopy and small intestine contrast ultrasonography in recurrence of Crohn's disease," Inflammatory Bowel Diseases, vol. 13, no. 10, pp. 1256-1265, 2007.

[42] C. Petruzziello, E. Calabrese, S. Onali et al., "Small bowel capsule endoscopy vs conventional techniques in patients with symptoms highly compatible with Crohn's Disease," Journal of Crohn's and Colitis, vol. 5, no. 2, pp. 139-147, 2011.

[43] S. L. Triester, J. A. Leighton, G. I. Leontiadis et al., "A metaanalysis of the yield of capsule endoscopy compared to other diagnostic modalities in patients with non-stricturing small bowel Crohn's disease," American Journal of Gastroenterology, vol. 101, no. 5, pp. 954-964, 2006.

[44] P. M. Dionisio, S. R. Gurudu, J. A. Leighton et al., "Capsule endoscopy has a significantly higher diagnostic yield in patients with suspected and established small-bowel crohn's disease: a meta-analysis," American Journal of Gastroenterology, vol. 105, no. 6, pp. 1240-1248, 2010.

[45] M. Tukey, D. Pleskow, P. Legnani, A. S. Cheifetz, and A. C. Moss, "The utility of capsule endoscopy in patients with suspected Crohn's disease," American Journal of Gastroenterology, vol. 104, no. 11, pp. 2734-2739, 2009.

[46] A. Bourreille, A. Ignjatovic, L. Aabakken et al., "Role of small-bowel endoscopy in the management of patients with inflammatory bowel disease: an international OMED-ECCO consensus," Endoscopy, vol. 41, no. 7, pp. 618-637, 2009.

[47] G. van Assche, A. Dignass, J. Panes et al., "The second European evidence-based consensus on the diagnosis and management of Crohn's disease: definitions and diagnosis," Journal of Crohn's and Colitis, vol. 4, no. 1, pp. 7-27, 2010.

[48] S. Mehdlzadeh, G. Chen, P. J. Enayati et al., "Diagnostic yield of capsule endoscopy in ulcerative colitis and inflammatory bowel disease of unclassified type (IBDU)," Endoscopy, vol. 40, no. 1, pp. 30-35, 2008.

[49] V. Maunoury, G. Savoye, A. Bourreille et al., "Value of wireless capsule endoscopy in patients with indeterminate colitis (inflammatory bowel disease type unclassified)," Inflammatory Bowel Diseases, vol. 13, no. 2, pp. 152-155, 2007.

[50] A. Bousvaros, D. A. Antonioli, R. B. Colletti et al., "Differentiating ulcerative colitis from Crohn disease in children and young adults: report of a working group of the North American Society for Pediatric Gastroenterology, Hepatology, and Nutrition and the Crohn's and Colitis Foundation of America," Journal of Pediatric Gastroenterology and Nutrition, vol. 44, pp. 653-674, 2007.

[51] A. Bourreille, M. Jarry, P. N. D’Halluin et al., "Wireless capsule endoscopy versus ileocolonoscopy for the diagnosis of postoperative recurrence of Crohn's disease: a prospective study," Gut, vol. 55, no. 7, pp. 978-982, 2006.

[52] V. Pons Beltrán, P. Nos, G. Bastida et al., "Evaluation of postsurgical recurrence in Crohn's disease: a new indication for capsule endoscopy?" Gastrointestinal Endoscopy, vol. 66, no. 3, pp. 533-540, 2007.

[53] G. van Assche, S. Vermeire, and P. Rutgeerts, "Medical treatment of inflammatory bowel diseases," Current Opinion in Gastroenterology, vol. 21, no. 4, pp. 443-447, 2005.

[54] D. Sorrentino, A. Paviotti, G. Terrosu, C. Avellini, M. Geraci, and D. Zarifi, "Low-dose maintenance therapy with infliximab prevents postsurgical recurrence of Crohn's disease," Clinical Gastroenterology and Hepatology, vol. 8, no. 7, pp. 591-599, 2010. 


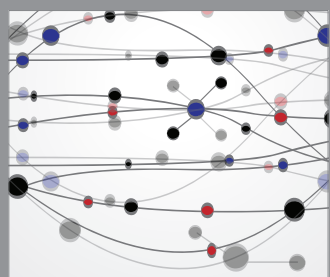

The Scientific World Journal
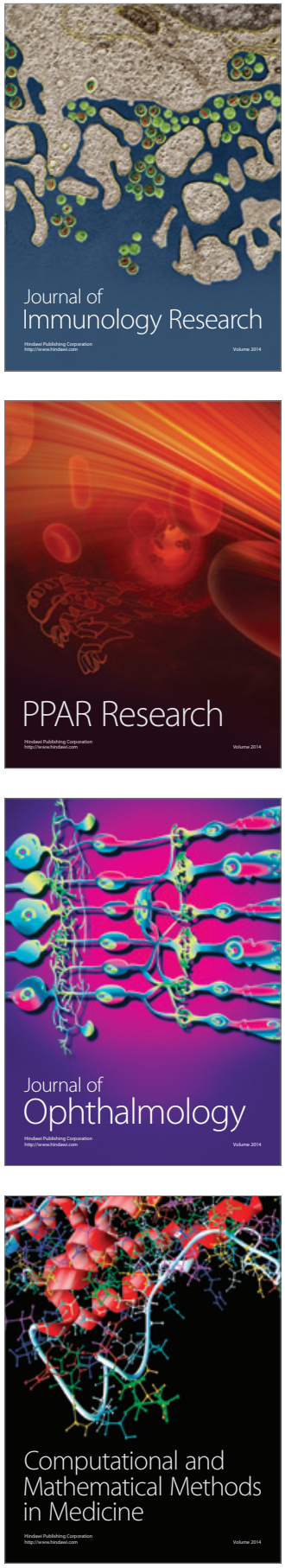

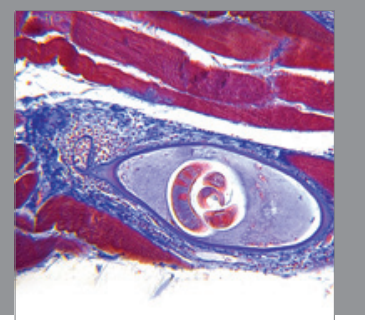

Gastroenterology

Research and Practice
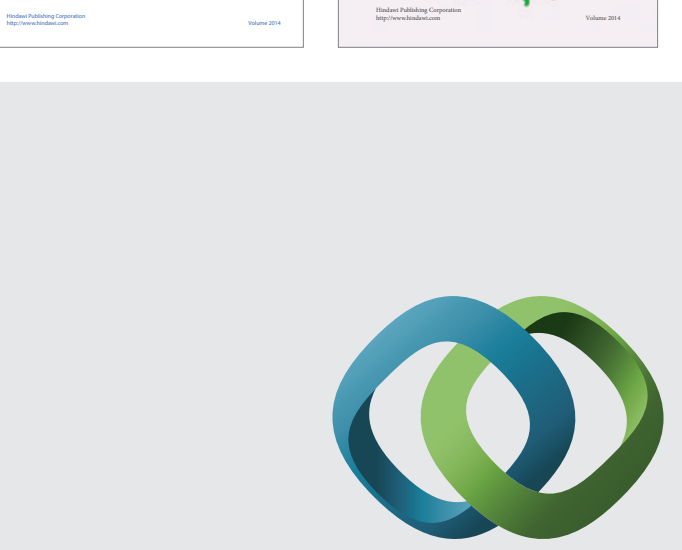

\section{Hindawi}

Submit your manuscripts at

http://www.hindawi.com
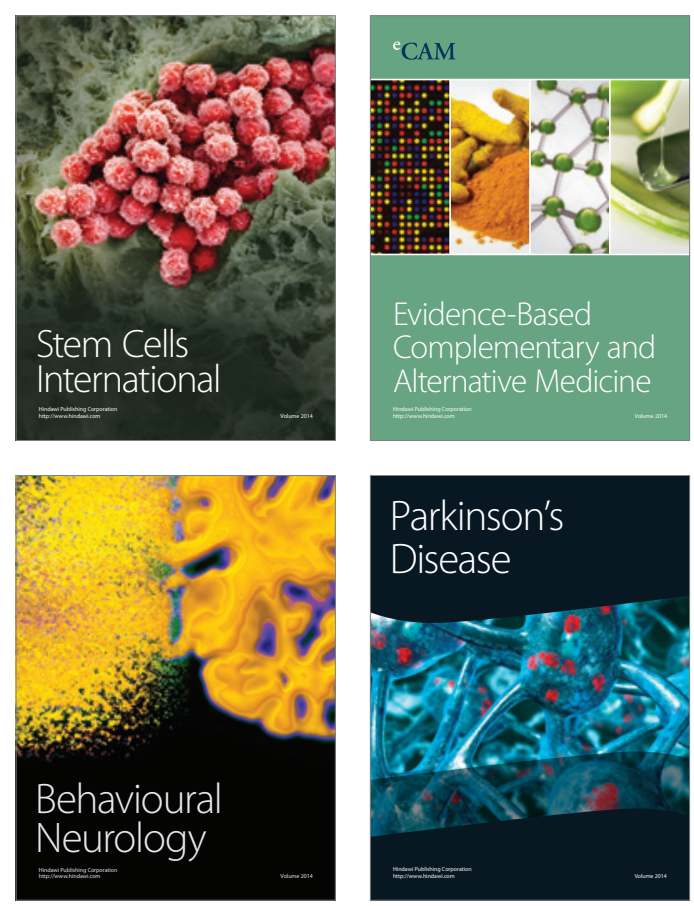

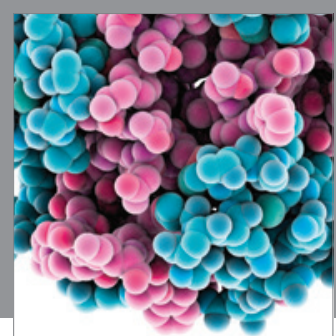

Journal of
Diabetes Research

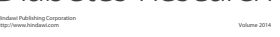

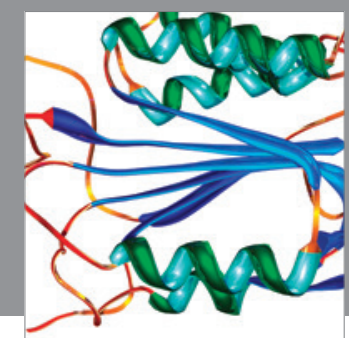

Disease Markers
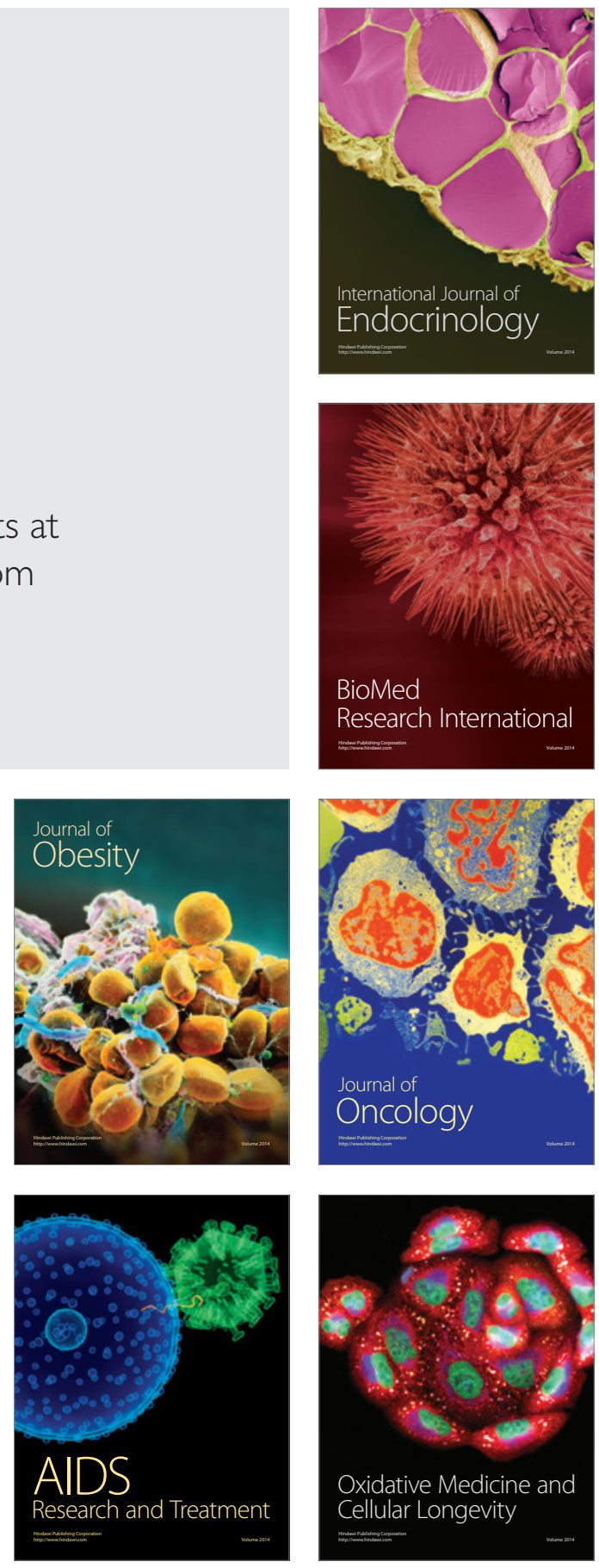